\title{
The second-to-fourth digit ratio correlates with the rate of academic performance in medical school students
}

\author{
MARINELLA COCO ${ }^{1}$, VALENTINA PERCIAVALLE ${ }^{2}$, TIZIANA MACI ${ }^{3}$, FERDINANDO NICOLETTI ${ }^{4}$, \\ DONATELLA DI CORRADO $^{5}$ and VINCENZO PERCIAVALLE ${ }^{1}$ \\ Departments of ${ }^{1}$ Physiological Sciences, ${ }^{2}$ Formative Processes, ${ }^{3}$ Neurosciences, and ${ }^{4}$ Biomedical Sciences, \\ University of Catania, Catania; ${ }^{5}$ Faculty of Sciences of Formation, University of Kore, Enna, Italy
}

Received January 3, 2011; Accepted February 15, 2011

DOI: $10.3892 / \mathrm{mmr} .2011 .456$

\begin{abstract}
Prenatal androgens have important organizing effects on the development and future behavior of the brain. The second-to-fourth digit length ratio (2D:4D) has been proposed as a marker of these prenatal androgen effects, with a relatively longer fourth finger indicating higher prenatal androgen exposure. 2D:4D has been shown to predict the success of men who play sports and of financial traders. However, to date little is known regarding the effects of prenatal androgens on academic performance, for example, admission to and success in a highly competitive university system such as the state-run Italian medical schools. Here, we report the findings of a study conducted at the University of Catania Medical School, Italy, in which the 2D:4D ratio was sampled in a group of 48 male students. The 2D:4D ratios were found to be correlated with the performance of the students on the admission test to the medical school, their salivary testosterone levels and their aggressiveness; however, no correlation was observed with the mean score on exams during the course of study. Our results suggest that pre and/or postnatal androgens increase performance in situations that require prompt decision-making and the ability to take risks, but do not influence performance when a more analytical and planned approach is called for.
\end{abstract}

\section{Introduction}

It has been argued that prenatal androgens influence the developing brain by increasing its later sensitivity to the effects of circulating testosterone (1-3). These effects may include increased self-confidence (4), search persistence (5) and risk preference (6-8), as well as intensified vigilance and quickened reaction times (9). Several markers have been proposed for evaluating the effects of prenatal androgens (10), but the

Correspondence to: Professor Vincenzo Perciavalle, Department of Physiological Sciences, University of Catania, Viale Andrea Doria 6, I-95125 Catania, Italy

E-mail:perciava@unict.it

Key words: digit ratio, competition, academic performance, aggressiveness, decision-making, testosterone most suitable is probably the second-to-fourth digit length ratio (2D:4D), with a relatively longer fourth finger (i.e., lower 2D:4D) indicating higher fetal androgens (11).

A recent study (12) concluded that, due to considerable within-group variability and between-group overlap, digit ratio is not a good marker of individual differences in prenatal androgen exposure. However, for its ease of measurement and reproducibility, 2D:4D is a good substitute measure of prenatal androgen exposure. Support for its use originates from the finding that digit growth and gonadal development are both influenced by the homeobox (Hox) genes $(11,13)$. There is evidence to suggest that sex steroids produced by the developing gonads exert important modulatory effects on digit growth (14). Lower digit ratios have also been shown to be correlated with the increased sensitivity of androgen receptors (15), and human male reproductive function has been negatively correlated with 2D:4D (16). Moreover, 2D:4D ratios appear to be predictive of performance in competitive sports, such as soccer (17), rugby, basketball (18) and skiing (19), and of success among high-frequency financial traders (20).

Digit ratio may also be predictive of achievement in other competitive situations. We therefore aimed to verify whether the 2D:4D ratio is capable of predicting admission to and success in state-run Italian medical schools. The academic course in the Italian medical schools offers particularly promising performance indicators in this respect. Two variables, the ranking position of the students on the admission test and the mean score obtained during the final exams at the end of each teaching unit, are objective and readily measured indicators of performance. The first is mainly indicative of prompt decision-making and the ability to take risks, whereas the second reflects planning abilities and a more methodical approach.

The present study was carried out to test the hypothesis that not only high levels of testosterone in adulthood, but also higher prenatal testosterone exposure, influence the performance of medical students. Specifically, we predicted that students with a lower 2D:4D would pass the admission test to the medical school more easily, and that less of an influence would be observed on exam scores during the course of study. To test this hypothesis, 48 male students were recruited from the University of Catania Medical School. The individual ranking of students based on their performance on the medical 
school admission test was used as the primary measure of their relative performance. Additionally, the mean score of students obtained in the final exams at the end of each teaching unit during their 6-year course was analyzed. It is worth noting that final exams are not multiple choice tests, rather traditional oral examinations. High scores in these exams are capable of influencing the probability of the students entering into specialization schools after achieving their MD. Finally, levels of testosterone in the saliva (Sal/T) of the participants as well as their aggressiveness were measured.

\section{Materials and methods}

Participants. Subjects in their second and third year of physiology studies at the University of Catania Medical School were invited to participate in the study. The students received an introductory brief explaining that the study was examining the effects of prenatal testosterone on the shape of their right hand. No information was provided regarding our hypothesis. Interested students were informed that they would receive a summary of our findings, but were not offered financial compensation.

Out of 52 students, 48 agreed to participate. As controls, handprints were obtained from 107 male students randomly selected from among 1,070 male individuals who did not pass the Medical School admission test. Before providing a handprint, the subjects completed a short questionnaire indicating their age, medical history and whether they had broken the index or ring finger of their right hand. Participants had a mean age of $20.8 \pm 1.04$ years, a mean height of $172.7 \pm 5.34 \mathrm{~cm}$ and a mean body mass of $73.4 \pm 8.33 \mathrm{~kg}$.

The study was approved by the Ethics Committee of the Medical School at the University of Catania. All participants signed an informed consent form.

Digit ratio measurement. To determine the 2D:4D ratio, photocopies of the right hands of the students were obtained. The digit length from the metacarpo-phalangeal crease (the most proximal between finger and palm) to the finger tip was measured. It has been observed that this crease appears around the ninth week of gestation, and is one of the primary creases of the hand (21).

The 2D:4D ratio was determined from right-hand measurements only, as right-hand digits have previously been shown to display more robust sex differences and are thus thought to be more sensitive to prenatal androgens $(22,23)$.

When measuring the 2D:4D ratio, practical recommendations suggested by Voracek et al were adopted (24). General procedures for 2D:4D measurement followed those recently described by Coates et al. (25). In soft tissue, care must be taken to distinguish regular from irregular or secondary creases. Irregular creases form later than regular creases after the eleventh week of gestation when the fingers start to bend, disrupting the dermal surface $(21,26)$. The handprints of the students were measured for 2D:4D by one of the authors (M.C.) using callipers accurate to $0.2 \mathrm{~mm}$.

Academic success. The curricula studiorum data for the 48 recruited students was obtained from the university database to obtain the performance indicators used in the present study: ranking position based on admission test performance and average exam scores. Concerning this preference, it is necessary to make some clarifications. In Italy, the content of the medical school admission test is decided each year by the Ministry of Education, Universities and Research (MIUR), and consists of eighty multiple choice questions divided in five categories: logics and general education, mathematics, physics, chemistry, and biology. Students must choose the correct answer from among five options. The general organization of the testing is similar to that of the Medical College Admission Test (MCAT).

Medicine is one of the university faculties where the overall number of students admitted every year is constant, as each medical school is assigned a maximum number of new admissions per year by the MIUR. The University of Catania Medical School accepts a maximum of 270 students per year. The test is usually taken in early September by approximately 3,000 students, but only those ranked in the first 270 positions can enroll. Each medical school administers the test separately, and the results are only valid for entry to the medical school where the test was taken. As a general rule, all state-run medical schools administer the test on the same day, whereas all privately-run medical schools administer it on another day, so that a candidate may take the test once at a state-run school and once at a private school of his/her choice, but no more.

The duration of Italian medical school is 6 years (12 semesters), and in most schools students take approximately 36 exams over the 6-year cycle. At the end of each teaching unit, there is a final exam comprising written amd/or oral questions. Students pass only by achieving a score of 18 or more out of a maximum score of 30 .

Hormone assessment. Saliva samples $(1 \mathrm{ml})$ were collected from subjects at rest in sterile containers and stored at $-80^{\circ} \mathrm{C}$. Sugar-free gum (Vivident Xylit ${ }^{\circledR}$ ) was used to increase saliva flow (27). Since, in adult males, the excretion of testosterone in saliva appears to follow a circadian rhythm (28) and be a pulsatile secretion (29), four samples were collected at intervals of 30 min between 9:00 and 12:00 a.m. Saliva was assayed using diagnostic kits (Diagnostic Systems Laboratories Inc., USA) and modified radioimmunoassay methods (30). Testosterone assay sensitivity was $0.3 \mathrm{pg} / \mathrm{ml}$ with intra- and inter-assay coefficients of variation of $<9.2 \%$ and $<8.3 \%$, respectively. Only the highest value of the four measures obtained from each subject was used for the experiments.

Picture Frustration Test. The Italian version of the Picture Frustration Test (PFT) (31-33) allows the assessment of a subject's preferred way of handling aggressive impulses. The subject is asked to react verbally to 24 illustrations of common frustrating situations by filling out an empty speech bubble for a character experiencing the frustration. The answers are assigned to three directions of aggression: 'extraggression', 'intraggression' and 'imaggression'. The types of aggression include attending to the frustrating barrier (obstacle dominance), defending the organization of personality (egodefense) or finding solutions (need-persistence), and some special indices. Descriptions of each factor are included in Table I, and are based on those of Tatsuki et al (34). 
Table I. Constructs of reaction to frustration.

\begin{tabular}{|c|c|c|c|}
\hline \multirow[t]{2}{*}{ Direction of aggression } & \multicolumn{3}{|c|}{ Type of aggression } \\
\hline & Obstacle-dominance (O-D) & Ego-defence (etho-defense) (E-D) & Need-persistence (N-P) \\
\hline Extragression (E-A) & $\begin{array}{l}\text { E1 (extrapeditive): } \\
\text { The presence of the frustrating } \\
\text { obstacle is (insistently) } \\
\text { pointed out. }\end{array}$ & $\begin{array}{l}E \text { (extrapunitive): } \\
\text { Blame and hostility are directed } \\
\text { at some person or thing in the } \\
\text { environment. } \\
\text { E (a variant of E): The subject } \\
\text { denies being responsible when } \\
\text { charged with an offense. }\end{array}$ & $\begin{array}{l}\text { e (extrapersistive): } \\
\text { A solution to the frustrating } \\
\text { situation is expected of } \\
\text { someone else. }\end{array}$ \\
\hline Intraggression (I-A) & $\begin{array}{l}\text { I1 (intropeditive): } \\
\text { The obstacle is construed to } \\
\text { be beneficial, even non- } \\
\text { frustrating, and the subject } \\
\text { may express embarrassment } \\
\text { at causing someone else } \\
\text { frustration. }\end{array}$ & $\begin{array}{l}\text { I (intropunitive): } \\
\text { Blame and censure are self- } \\
\text { directed by the subject. } \\
\text { I (a variant of I): The subject } \\
\text { admits guilt but denies any } \\
\text { essential fault by referring to } \\
\text { unavoidable circumstance. }\end{array}$ & $\begin{array}{l}\text { i (intropersistive): } \\
\text { Amends are offered by the } \\
\text { subject, usually due to a sense } \\
\text { of guilt, to solve the problem. }\end{array}$ \\
\hline Imaggression (M-A) & $\begin{array}{l}\text { M1 (impeditive): } \\
\text { The frustrating obstacle is } \\
\text { minimized, almost to the point } \\
\text { of denying its existence. }\end{array}$ & $\begin{array}{l}\text { M (impunitive): } \\
\text { Blame for the frustration is } \\
\text { evaded altogether. The } \\
\text { situation is regarded as } \\
\text { unavoidable; the frustrating } \\
\text { individual is absolved. }\end{array}$ & $\begin{array}{l}\text { m (impersistive): } \\
\text { Hope is expressed that time or } \\
\text { normally expected circumstan- } \\
\text { ces will bring about a solution } \\
\text { to the problem; patience and } \\
\text { conformity are characteristic. }\end{array}$ \\
\hline
\end{tabular}

Statistical analysis. Data are presented as the mean \pm standard deviation. Data were collected and averaged, then compared using the unpaired Student's t-test or one-way repeated-measures ANOVA (Friedman test) followed by Dunn's Multiple Comparison Test. Correlation analysis was carried out using one-tailed Pearson's correlation analysis, and significance was set at $\mathrm{P}<0.05$. Analyses were performed using Systat software version 11 (Systat Inc., Evanston, IL, USA) and were carried out according to the guidelines for reporting statistics in journals published by the American Physiological Society (35).

\section{Results}

We first examined the frequency distribution of the 2D:4D ratios measured in the 48 students and 107 controls. As can be seen in Fig. 1, in both samples, a normal distribution was obtained with a mean value of $0.99 \pm 0.04$ for students and of $1.02 \pm 0.07$ for controls. The unpaired Student's t-test (twotailed) showed that the observed difference was statistically significant $(\mathrm{P}=0.0119)$.

Subsequently, the correlation between the 2D:4D ratio and the ranking position obtained by the 48 students based on the medical school admission test was analyzed (Fig. 2A). According to our hypothesis, students with a lower 2D:4D would have passed the admission test more easily and would have achieved a better position in the ranking. Indeed, the results showed that the lower a student's $2 \mathrm{D}: 4 \mathrm{D}$ ratio, the better his position in the final ranking $(\mathrm{P}=0.002)$. The $2 \mathrm{D}: 4 \mathrm{D}$ ratio of the students was also analyzed with respect to their

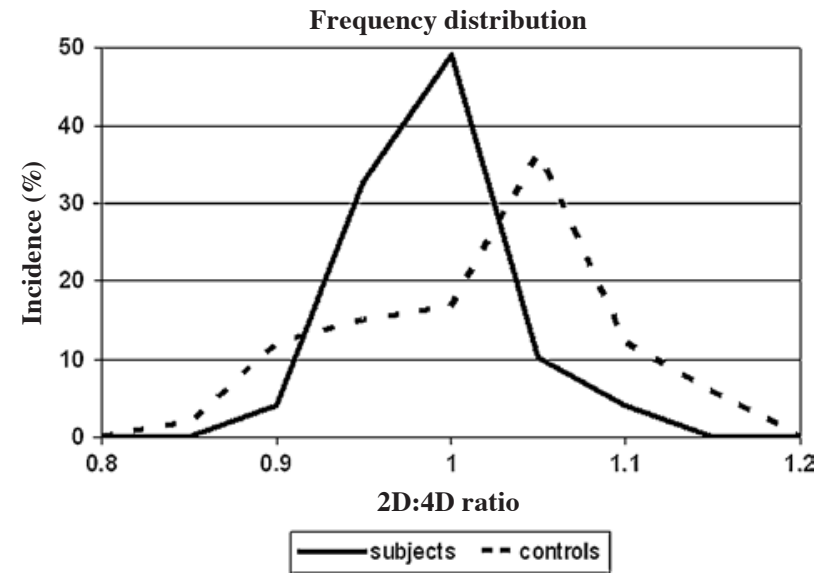

Figure 1. Frequency distribution of digit ratio (2D:4D) measured in 48 students and 107 controls. In both cases, a normal distribution was obtained, with a mean value of $0.99 \pm 0.04$ for students and of $1.02 \pm 0.07$ for controls The unpaired Student's t-test (two-tailed) showed that the observed difference was statistically significant $(\mathrm{P}=0.0119)$.

mean score in the final exams at the end of each teaching unit (Fig. 2B). No significant correlation between digit ratio and mean score in the exams was found $(\mathrm{P}=0.514)$.

Additionally, possible correlations between the 2D:4D ratio of the sample and their salivary testosterone concentration (Sal/T) were examined. The mean Sal/T of the students was $20.0 \pm 7.73 \mathrm{pg} / \mathrm{ml}$. As shown in Fig. 2B, a significant negative correlation between the two variables was observed 
A

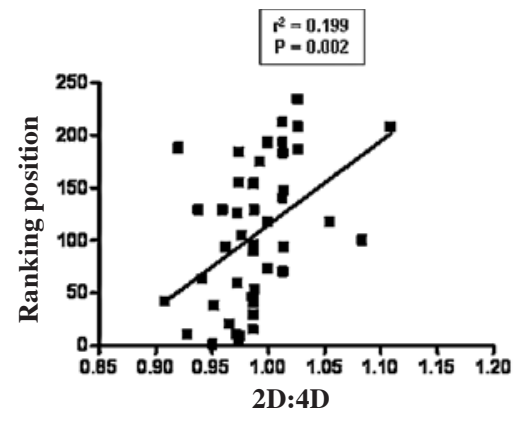

C

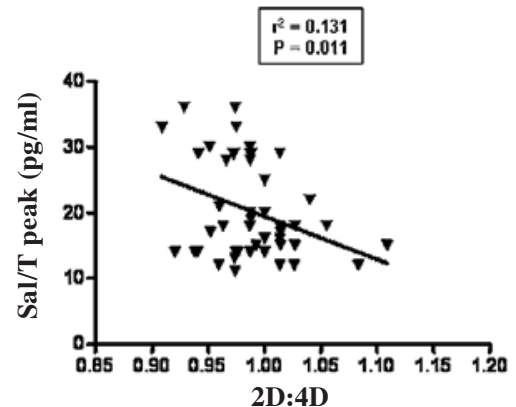

B

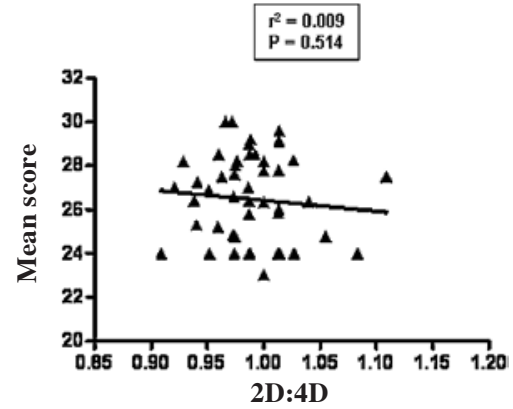

D

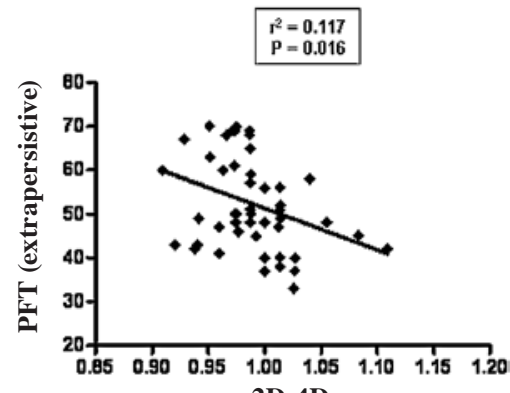

Figure 2. Digit ratio (2D:4D) and admission to success in medical school. (A) Ranking position obtained by students based on their medical school admission test results plotted against their 2D:4D ratio. (B) 2D:4D ratio of students plotted against their mean exam score obtained during the course of their academic career. (C) 2D:4D ratio of students plotted against their testosterone concentration in saliva (Sal/T). (D) 2D:4D ratio of students plotted against their extrapersistive aggressiveness.

Table II. Correlation between RPF scores and 2D:4D ratio

\begin{tabular}{lcc}
\hline RPF test & Pearson R & P-value \\
\hline Intraggression & & \\
Intropeditive & 0.036 & $\mathrm{NS}$ \\
Intropunitive & 0.021 & $\mathrm{NS}$ \\
Intropersistive & 0.012 & $\mathrm{NS}$ \\
Imaggression & & \\
Impeditive & 0.036 & $\mathrm{NS}$ \\
Impunitive & 0.019 & $\mathrm{NS}$ \\
Impersistive & 0.034 & $\mathrm{NS}$ \\
Extraggression & & \\
Extrapeditive & 0.044 & $\mathrm{NS}$ \\
Extrapunitive & 0.032 & $\mathrm{NS}$ \\
Extrapersistive & 0.342 & $<0.05$
\end{tabular}

NS, non significant; RPF, Rosenzweig Picture Frustration test.

$(\mathrm{P}=0.011)$. When the 2D:4D ratio of the students was plotted against their extrapersistive aggressiveness (one of the extraggression characteristics from the PFT test), a significant negative correlation was observed between the two variables $(\mathrm{P}=0.016)$ (Fig. 2B). However, the other extraggression scores (extrapeditive and extrapunitive) had no significant correlation with the $2 \mathrm{D}: 4 \mathrm{D}$ ratio, nor did the intraggression and imaggression scores (Table II).

Finally, Sal/T values were correlated with position, mean score and aggressiveness. As can be seen in Fig. 3, a significant correlation $(\mathrm{P}<0.001)$ between $\mathrm{Sal} / \mathrm{T}$ and both ranking and aggression was detected in the students, whereas no
A

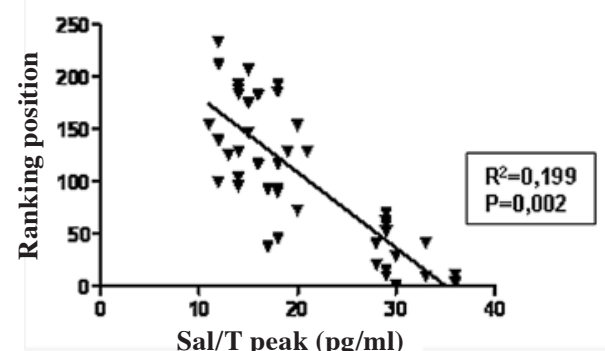

B

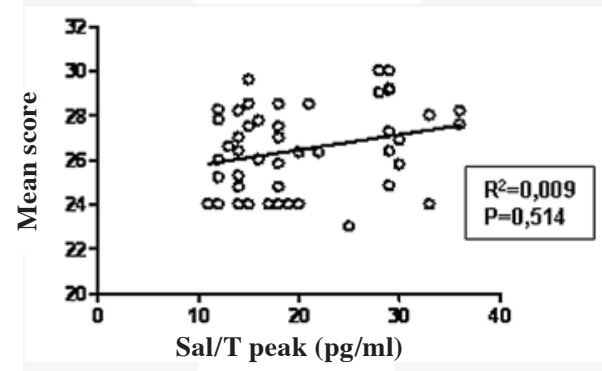

C

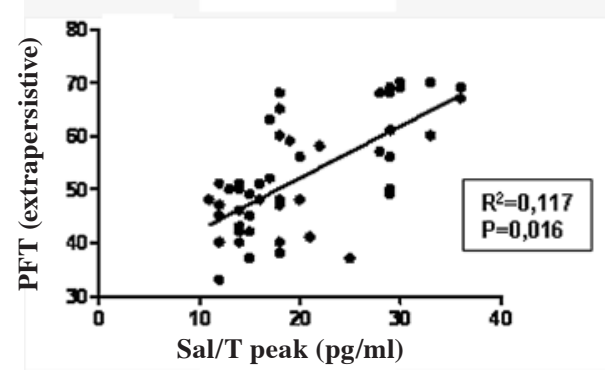

Figure 3. Testosterone concentration in saliva (Sal/T) and admission to and success in medical school. (A) Ranking position obtained by students based on their medical school admission test results, plotted against their (Sal/T). (B) Sal/T of students plotted against their mean exam score obtained during the course of their academic career. (C) Sal/T of students plotted against their extrapersistive aggressiveness. 
correlation was observed between Sal/T and the mean score of the sample.

\section{Discussion}

Analysis of the data from our male sample revealed that the students had a slightly lower 2D:4D ratio of the right hand, significantly lower than that of those who failed the medical school admission test. Moreover, a significant negative correlation was found between the 2D:4D ratios of the students and both salivary testosterone levels and extrapersistive aggressiveness. Finally, a significant correlation was detected between Sal/T and both ranking and aggression, but not with mean exam scores.

Our results confirm the relationship between testosterone levels and 2D:4D ratios, and support the hypothesis that 2D:4D ratios predict improved performance in admission tests, but not in exams undertaken during the academic period.

It has previously been observed that there is a significant correlation between 2D:4D ratios and salivary testosterone levels in adult men (36). However, no significant correlation was observed between digit ratio and reactive aggression. The discrepancy may be due to the different methods used for measuring aggression; in the present study, we used a validated and widely used test, the PFT, whereas Benderlioglu and Nelson (36) utilized an adaptation of the methods of Kulik and Brown (37), which are less widespread and not yet validated.

The relationship between baseline testosterone concentrations and aggressiveness detected in the present study has been previously observed (38-40), although certain studies have failed to replicate this finding $(41,42)$. This contradictory data regarding aggression may be due in part to the use of self-report measures as opposed to the direct measurement of aggressive behavior (43). Furthermore, circadian rhythm (28), pulsatile secretion (29) or dynamic fluctuations (44) in testosterone concentrations may be more related to aggressive behavior than mean daily testosterone concentrations. To minimize these possible errors, for the evaluation of aggression we directly measured the aggression of the students using the PFT, and testosterone collection was carried out between 9:00 and 12:00 a.m., with four samples collected at intervals of $30 \mathrm{~min}$. Only the highest value of the four measures obtained from each subject was used for the present experiments.

As pointed out by Carré et al (45), a role for baseline testosterone in decision-making was observed among men performing the Ultimatum Game (46), in which two players have to decide how to divide a sum of money. The first player proposes how to divide the sum between the two players, and the second player (the receiver) can either accept or reject this proposal. If the second player rejects, neither player receives anything. If the second player accepts, the money is split according to the proposal. In this game, the logical option is for the receiver to accept any offer made by the proposer, because any money earned is better than no money at all. Burnham (47) reported that men with high testosterone were more likely to reject low offers than men with low testosterone. Although this may seem to be an unfavorable decision, the rejection appears to be based on the desire to punish unfair actions (48). Thus, the cost of reactive aggression may be compensated by emotional advantages. Josephs et al (41) proposed that men with high testosterone may be distracted by their desire to regain lost status and, as a consequence, perform relatively poorly on cognitive tasks. These findings suggest that when provoked (by low offers), men with high testosterone are more likely to have impaired performance in decision-making tasks. By contrast, in the absence of direct provocation, testosterone may have a positive effect on the likelihood of gaining a reward. For example, male stock traders were found to have greater profits on days in which their blood testosterone levels were elevated (25).

As suggested by Coates et al (20), there is a roughly even split between the contributions of biology and experience; biology in this case being the organizing effects of prenatal androgens on the body, brain and behavior of an individual. As digit ratios are set early in life, there can be no experience-based feedback mechanism; digit ratios predict success in admission, not vice versa. Students with a low 2D:4D ratio appear to have higher salivary testosterone levels and to be more capable of managing conditions that require prompt decision-making, determination, acceptation of risk and/or audacity in the face of novelty. However, the correlation may even be reversed among students who adopt a more analytical and planned approach to study. For example, Brosnan (49) analyzed average digit ratios in university departments and found that students in the faculties of math, science and engineering exhibited higher 2D:4D ratios. A similar result may well be found among students with a long-term study period requiring high efficiency. It would be of interest to perform a follow-up of these students to analyze the correlation between their 2D:4D ratio and their professional performance as physicians after graduation; in particular, which students undertook medical specializations that require prompt decision-making and ability to take risks, e.g., the emergency department, as opposed to those that require a more methodical and planned approach.

In conclusion, this study indicates that, in young men, aggressive and risk-taking behavior is more likely in individuals with high testosterone levels not only in adulthood, but also during their intrauterine life.

\section{Acknowledgements}

The authors thank the students for participating in this study, thereby making it possible. M.C., Va.P., T.M., D.D.C. and Vi.P. performed the research; M.C., Va.P. and Vi.P. designed the research study; M.C., F.M. and Vi.P. analyzed the data; and Vi.P. wrote the paper.

\section{References}

1. Breedlove SM and Hampson E: Sexual differentiation of the brain and behaviour. In: Behavioral Endocrinology. 2nd edition. Becker J, Breedlove SM, Crews D and McCarthy MM (eds). MIT Press, Cambridge, MA, pp75-114, 2002.

2. Goy R and McEwen BS: Sexual Differentiation of the Brain. MIT Press, Cambridge, MA, p236, 1980.

3. Tobet S and Baum M: Role for prenatal estrogen in the development of masculine sexual behavior in the male ferret. Horm Behav 21: 419-429, 1987.

4. Boissy A and Bouissou M: Effects of androgen treatment on behavioural and physiological responses of heifers to feareliciting situations. Horm Behav 28: 66-83, 1994.

5. Andrew R and Rogers L: Testosterone, search behaviour and persistence. Nature 237: 343-346, 1972. 
6. Apicella CL, Dreber A, Campbell B, Gray PB, Hoffman M and Little AC: Testosterone and financial risk preferences. Evol Hum Behav 29: 384-390, 2008.

7. Booth A, Johnson D and Granger D: Testosterone and men's health. J Behav Med 22: 1-19, 1999.

8. Van Honk J, Schutter DJ, Hermans EJ, Putman P, Tuiten A and Koppeschaar $\mathrm{H}$ : Testosterone shifts the balance between sensitivity for punishment and reward in healthy young women. Psychoneuroendocrinology 29: 937-943, 2004

9. Salminen E, Portin R, Koskinen A, Helenius H and Nurmi M: Associations between serum testosterone fall and cognitive function in prostate cancer patients. Clin Cancer Res 10 7575-7582, 2004.

10. Cohen-Bendahana $\mathrm{C}$, van de Beeka $\mathrm{C}$ and Berenbaum S: Prenatal sex hormone effects on child and adult sex-typed behavior: methods and findings. Neurosci Biobehav Rev 29: 353-384, 2005.

11. Manning JT, Scutt D, Wilson J and Lewis-Jones DI: The ratio of 2nd to 4th digit length: a predictor of sperm numbers and concentrations of testosterone, luteinizing hormone and oestrogen. Hum Reprod 13: 3000-3004, 1998.

12. Berenbaum SA, Bryk KK, Nowak N, Quigley CA and Moffat S: Fingers as a marker of prenatal androgen exposure. Endocrinology 150: 5119-5124, 2009.

13. Paul SN, Kato BS, Cherkas LF, et al: Heritability of the second to fourth digit ratio $(2 \mathrm{~d}: 4 \mathrm{~d})$ : a twin study. Twin Res Hum Genet 9: $215-219,2006$.

14. McIntyre M: The use of digit ratios as markers for perinatal androgen action. Reprod Biol Endocrinol 4: 10-19, 2006.

15. Manning JT, Bundred PE, Newton DJ and Flanagan BF: The 2nd to 4th digit ratio and variation in the androgen receptor gene. Evol Hum Behav 24: 399-405, 2003.

16. Auger $\mathrm{J}$ and Eustache F: Second to fourth digit ratios, male genital development and reproductive health: a clinical study among fertile men and testis cancer patients. Int $\mathrm{J}$ Androl Nov 23, 2010, doi: 10.1111/j.1365-2605.2010.01124.x (E-pub ahead of print).

17. Manning JT and Taylor RP: Second to fourth digit ratio and male ability in sport: implications for sexual selection in humans. Evol Hum Behav 22: 61-69, 2001.

18. Tester N and Campbell A: Sporting achievement: what is the contribution of digit ratio? J Pers 75: 663-677, 2007.

19. Manning JT: The ratio of 2 nd to 4th digit length and performance in skiing. J Sports Med Phys Fitness 42: 446-450, 2002.

20. Coates JM, Gurnell M and Rustichini A: Second-to-fourth digit ratio predicts success among high-frequency financial traders Proc Natl Acad Sci USA 106: 623-628, 2009.

21. Kimura S, Schaumann B, Plato C and Kitagawa T: Embryological development and prevalence of digital flexion creases. Anat Rec 226: 249-257, 1990.

22. Manning JT, Churchill AJ and Peters M: The effects of sex, ethnicity, and sexual orientation on self-measured digit ratio (2D:4D). Arch Sex Behav 36: 223-233, 2007.

23. Williams TJ, Pepitone ME, Christensen SE, et al: Finger-length ratios and sexual orientation. Nature 404: 455-456, 2000

24. Voracek M, Bagdonas A and Dressler SG: Digit ratio (2D:4D) in Lithuania once and now: testing for sex differences, relations with eye and hair color, and a possible secular change. Coll Antropol 31: 863-868, 2007.

25. Coates $\mathrm{J}$ and Hebert J: Endogenous steroids and financial risk taking on a London trading floor. Proc Natl Acad Sci USA 105 6167-6172, 2008

26. Ashbaugh D: The identification process. In: QuantitativeQualitative Friction Ridge Analysis: An Introduction to Basic and Advanced Ridgeology. CRC Press, Boca Raton, FL, p234, 1999.
27. Dabbs JM Jr: Salivary testosterone measurements: collecting, storing, and mailing saliva samples. Physiol Behav 49: 815-817, 1991.

28. Landman AD, Sanford LM, Howland BE, Dawes C and Pritchard ET: Testosterone in human saliva. Experientia 32: 940-941, 1976.

29. Keenan DM and Veldhuis JD: Disruption of the hypothalamic luteinizing hormone pulsing mechanism in aging men. Am J Physiol Regul Integr Comp Physiol 281: R1917-R1924, 2001.

30. Granger DA, Schwartz EB, Booth A and Arentz M: Salivary testosterone determination in studies of child health and development. Horm Behav 35: 18-27, 1999.

31. Rosenzweig S: Aggressive behavior and the Rosenzweig PictureFrustration (P-F) Study. J Clin Psychol 32, 885-891, 1976.

32. Rosenzweig S: PFS: Picture-Frustration Study: Manuale Integrato Delle Tre Forme Per Adulti, Bambini e Adolescenti. Organizzazioni Speciali, Firenze, 1992.

33. Rauchfleisch U: Handbuch zum Rosenzweig Picture-Frustration Test (PFT). Huber, Bern, p399, 1979.

34. Tatsuki DH: If my complaints could passions move: an interlanguage study of aggression. J Pragm 32: 1003-1017, 2000.

35. Curran-Everett D and Benos DJ: Guidelines for reporting statistics in journals published by the American Physiological Society. Am J Physiol Regul Integr Comp Physiol 97: 457-459, 2004.

36. Benderlioglu $Z$ and Nelson RJ: Digit length ratios predict reactive aggression in women, but not in men. Horm Behav 46: 558-564, 2004.

37. Kulik JA and Brown R: Frustration, attribution of blame, and aggression. J Exp Social Psychol 15: 183-194, 1979.

38. Dabbs JM Jr, Carr TS, Frady RL and Riad JK: Testosterone, crime, and misbehavior among 692 male prison inmates. Pers Indiv Diff 18: 627-633, 1995.

39. Archer J: Testosterone and human aggression: an evaluation of the challenge hypothesis. Neurosci Biobehav Rev 30: 319-345, 2006.

40. Sellers JG, Mehl MR and Josephs RA: Hormones and personality: testosterone as a marker of individual differences. J Res Per 41: 126-138, 2007

41. Josephs RA, Sellers JG, Newman ML and Mehta PH: The mismatch effect: when testosterone and status are at odds. J Exp Social Psychol 90: 999-1013, 2006.

42. Stanton S and Schultheiss O: Basal and dynamic relationship between implicit power motivation and estradiol in women. Horm Behav 52: 571-580, 2007.

43. Klinesmith J, Kasser T and McAndrew F: Guns, testosterone and aggression: an experimental test of a mediational hypothesis. Psychol Sci 179: 568-571, 2006.

44. Hermans E, Ramsey M and van Honk J: Exogenous testosterone enhances responsiveness to social threat in the neural circuitry of social aggression in humans. Biol Psychiatry 63: 263-270, 2008.

45. Carré JM, Putnam SK, McCormick CM: Testosterone responses to competition predict future aggressive behaviour at a cost to reward in men. Psychoneuroendocrinology 34: 561-570, 2009.

46. Güth W, Schmittberger R and Schwarze B: An experimental analysis of ultimatum bargaining. J Econ Behav Org 3: 367-388, 1982.

47. Burnham T: High testosterone men reject low ultimatum game offers. Proc Biol Sci 274: 2327-2330, 2007.

48. Ohmura Y and Yamagishi T: Why do people reject unintended inequity? responders' rejection in a truncated ultimatum game. Psychol Rep 96: 533-541, 2005.

49. Brosnan M: Digit ratio and faculty membership: implications for the relationship between prenatal testosterone and academia. Br J Psychol 97: 455-466, 2006. 